\title{
Site fidelity of Hippocampus guttulatus Cuvier, 1829 at Mar Piccolo of Taranto (Southern Italy; Ionian Sea)
}

\author{
Cataldo Pierri $\mathbb{D} \cdot$ Tamara Lazic $\mathbb{D} \cdot$ - Giuseppe Corriero $\mathbb{D} \cdot$ Frine Cardone $\mathbb{D}$ - Senem \\ Onen Tarantini $(\mathbb{D})$ Andrea Desiderato $(\mathbb{D}) \cdot$ Simone Mirto $(\mathbb{D})$ Michele Gristina
}

Received: 16 January 2020 /Revised: 28 May 2020 / Accepted: 12 July 2020 /Published online: 21 July 2020

(C) The Author(s) 2020

\begin{abstract}
Lack of detailed knowledge on ecological niche, life cycles, spatial distribution, reproductive biology and space use strongly affects the selection of useful tools and measures in the conservation of threatened marine species. Especially for sedentary and slow species, behaviour and movement capacities are supposed to be the most important functional traits. Indeed, behavioural variability concerning available space and the close presence of individuals is considered a crucial trait for the population dynamics assessments, especially when disturbances of various causes are present in the environment. The present study aimed to investigate the site fidelity and degree of movement of Hippocampus guttulatus, an emblematic and threatened Mediterranean
\end{abstract}

C. Pierri · T. Lazic $\cdot$ G. Corriero $\cdot$ S. Onen Tarantini Department of Biology, University of Bari, Bari, Italy

T. Lazic $(\bowtie) \cdot$ S. Onen Tarantini

CoNISMa, Rome, Italy

e-mail: tamaralazic90@yahoo.com

F. Cardone

Department of Integrated Marine Ecology, Stazione Zoologica Anton Dohrn, Naples, Italy

A. Desiderato

Department of Zoology, Universidade Federal do Paraná, Curitiba, Brazil

\section{S. Mirto $\cdot$ M. Gristina}

Institute of Anthropic Impacts and Sustainability in Marine Environment, National Research Council (IAS-CNR), Palermo, Italy seahorse species. With this aim, a number of seahorses were tagged and monitored throughout two years within a limited area of the lagoon of Mar Piccolo of Taranto (Southern Italy). The studied individuals were initially morphometrically measured for size, sex and life-cycle stage and subsequently monitored through repeated fourmonth surveys each year. Obtained results indicated high site fidelity regardless of habitat type. Movement pattern was in line with the data on congeneric species, although values were slightly higher. The analyses showed differences in movement degree among different sexes and life-cycle stages and indicated greater mobility of adult females compared to males and juveniles. The investigated parameters showed a great variability suggesting that even small-scale environmental factors can influence the species mobility. Finally, a change in the population structure has been observed, with the loss of large individuals in 2016 and reduced recruitment in 2017. These findings indicated the possible presence of stressors that could lead to the alteration of the seahorse population at Mar Piccolo of Taranto.

Keywords Long-snouted seahorse · Home range, · Space use $\cdot$ Conservation

\section{Introduction}

One of the fundamental challenges at the forefront of marine conservation biology is to understand the demographic dynamics of endangered species and how these dynamics affect the consistency, resilience, and 
recovery of local populations (Oro 2013). A large amount of data is requested to achieve this, including both abiotic data for the study of the ecological niche and biotic data necessary for the definition of biological cycles, distribution and environmental interactions. The scarcity of data on ecological niches, reproductive biology and species distribution in the marine environment severely constrains the design of effective conservation measures to oppose effects of habitat degradation, overfishing and climate changes (Klein et al. 2013; Selig et al. 2014). An even greater challenge arises when dealing with species with peculiar life-cycle traits, such as sedentary behaviour and specialized nutrition (Foster and Vincent 2004). Evaluation of movements in space and time is, indeed, considered as an essential trait for efficient management and conservation (Pittman and McAlpine 2003; Botsford et al. 2009). Especially in cryptic and sedentary marine species, temporal variability in movement behaviour (e.g. site fidelity and home range) might be relevant for ecological surveys reflecting the impacts of anthropogenic activities (Burger and Gochfeld 2001). Temporal variability occurs at different time scales (i.e. annual, seasonal, daily), thus influencing the estimates of abundance and distribution (Naylor 2005; Willis et al. 2006). Species move according to the needs for better reproduction, growth and survival, and the less movement they need to fulfil these requirements, smaller is the space used. However, the space used by species may be influenced by many factors, such as environmental fluctuations (Gehring and Swihart 2004), resource distribution (Hansen and Closs 2005), population density (Kjellander et al. 2004) and sex- (Jones et al. 2003) and body size-dependent energetic requirements (Haskell et al. 2002; Brown et al. 2004).

Seahorses represent a good example of sedentary marine fish that have peculiar morphology and lifecycle traits. They have low swimming capabilities and are characterized by monogamy, male pregnancy and lengthy parental care (Curtis and Vincent 2006). These traits, correlated with energy constraints, involve the limited use of space and reduced movements, even in stressful conditions (Caldwell and Vincent 2012). Therefore, examining how and to which extent seahorses use space can provide a better understanding not only of their behavioural diversity but also of surrounding ecological processes. Although threatened mostly because of their particular life-cycle traits, seahorses are having an almost worldwide distribution
(Lourie et al. 2016). The long-snouted seahorse H. guttulatus Cuvier, 1829 can be found throughout most of Europe and northern Africa, including the Atlantic Ocean, the Mediterranean and the Black Sea (Lourie et al. 1999; Lourie et al. 2016). Like all seahorse species, it mostly practices ambush predation, but can also adopt active predation tactics when searching for the prey in the water column or on phanerogams beds (Curtis and Vincent 2005; Ape et al. 2019). It shows a tendency to occupy sheltered and complex coastal habitats, although can be found in less complex habitats as well, at a depth from only a few centimetres to approximately $20 \mathrm{~m}$ of depth (Lazic et al. 2018). In conservation terms, this feature can be interpreted as positive, since species able to occupy several habitats may be less prone to extinction (Clark 2000; Gage et al. 2004; Işik 2011). However, according to the IUCN Red List, the species is currently recognized as 'Data Deficient' at a global level (Pollom 2017), while 'Near Threatened' in the Mediterranean Sea and along the Italian coast (Pollom 2016; Relini et al. 2017). Unsurprisingly, data on population status are available for only a small number of sites throughout the entire species range. The most comprehensive data come from the studies undertaken in Ria Formosa lagoon in Portugal (Caldwell and Vincent 2012; Correia 2015; Curtis and Vincent 2005), Étang de Thau in France (Louisy 2011) and Mar Piccolo of Taranto in Italy (Gristina et al. 2015, 2017; Lazic et al. 2018; Ape et al. 2019). The lagoon of Mar Piccolo of Taranto, together with Étang de Thau, hosts the most abundant seahorse populations in the Mediterranean Sea (Curtis and Vincent 2005; Caldwell and Vincent 2012; Gristina et al. 2015; Lazic et al. 2018). Although there was an increased scientific interest in the last years, the knowledge on movement patterns, their determinants, and temporal variability in changing environment, though on the site fidelity and capacity to migrate from one habitat to another, is still limited (Curtis and Vincent 2006; Garrick-Maidment et al. 2010; Caldwell and Vincent 2013). Up to date, mark-recapture studies highlighted that the long-snouted seahorses usually exhibit high site fidelity and small home ranges (Curtis and Vincent, 2006), but can travel longer distances due to the environmental factors, such as food availability or demographic changes (Caldwell and Vincent 2012).

Using data from seahorses throughout two consecutive years, the aims of the present study were to (i) investigate the degree of spatial and temporal site fidelity so to characterize movement patterns, and (ii) better 
understand potential factors driving space use of the threatened long-snouted seahorses in the Mar Piccolo of Taranto lagoon. By adding new ecological information, the final aim of this research was to fill the existing knowledge gap to inform management and conservation plans for the threatened species.

\section{Materials and methods}

The present study was carried out in the marine lagoon of Mar Piccolo of Taranto $\left(40^{\circ} 28^{\prime} \mathrm{N}, 17^{\circ} 16^{\prime} \mathrm{W}\right)$ in Southern Italy. The study site (Fig. 1) is a shallowwater area characterized by a continuous reinforced concrete wall all along the coastline; the area is relatively heterogeneous due to the presence of various habitats, such as artificial hard substrates (the wall), rocky and sandy bottom. Artificial hard substrates along the coastline are colonized by algal assemblages principally constituted of perennial Cystoseira C. Agardh, 1820 spp. and other frondose algae, such as Corallina elongata J.Ellis \& Solander 1786, Dictyota dichotoma (Hudson) J.V. Lamouroux 1809, and by bivalves, sabellid and serpulid annelids, ascidians, sponges, bryozoans and hydrozoans (for further description see Gristina et al. $2015,2017)$. The rocky bottom is located near the coastline and forms a belt of approximately four meters in width. It is characterized by the presence of sparse small rocks and sporadic artificial objects (e.g., ropes and iron poles) lying on the sand. Both natural and artificial structures are usually covered by algal turfs and other sessile organisms, while underlying sand is rich in mollusc shells originating from nearby mussel farms. Subsequently spreads the sandy bottom, at approximately two meters of depth, that is patchily colonized by sabellid polychaetes (e.g. Acromegalomma Gil \& Nishi, 2017 spp., Branchiomma luctuosum (Grube, 1870), Myxicola infundibulum (Montagu, 1808), Sabella spallanzanii (Gmelin, 1791), S. pavonina Savigny, 1822).

This study was conducted in two different periods, from October 2016 (seawater temperature $20 \pm 0.2{ }^{\circ} \mathrm{C}$ ) to January 2017 (seawater temperature $14 \pm 1.1{ }^{\circ} \mathrm{C}$ ) (namely 2016; 17 survey events) and from October 2017 (seawater temperature $18 \pm 0.8{ }^{\circ} \mathrm{C}$ ) to January 2018 (seawater temperature $12 \pm 0.4{ }^{\circ} \mathrm{C}$ ) (namely 2017; 16 survey events). Three continuous stations $\left(18 \times 10 \mathrm{~m}\right.$ each, $540 \mathrm{~m}^{2}$ in total; Fig. 1) were established to monitor $H$. guttulatus during both survey periods. Each station was divided into $2 \times 2 \mathrm{~m}$ grids using a mesh and fixed references placed at the vertices of each grid. The centroid of each grid was georeferenced for subsequent analyses. All habitats present in the area were classified into one of the following major categories: Vertical Substrates (VS), Sandy Bottoms (SB), Sandy Bottom with Holdfasts (SBH) or Sandy Bottom with Rocks (SBR).

All seahorses encountered inside the stations were tagged using degradable PDS (polydioxanone) surgical suture collars with a numbered plastic tag. Duration of PDS collars in seawater was a priori examined in the laboratory, demonstrating stable material properties for four months. Therefore, the present study had a comparable duration to ensure that the collars would not be lost before the end of the experiment. All tagging operations were carried out underwater, and all seahorses were gently handled for the minimum time to reduce stress. The habitat of occurrence for each individual was determined directly in the field. Simultaneously, standard length (SL) and sex were recorded by photographing seahorses with a ruler placed as close as possible (Curtis et al. 2004). Specimens were considered juveniles if they were $<50 \%$ size at maturity, corresponding to a $\mathrm{SL}$ of $96.0 \pm 8.0 \mathrm{~mm}$ (mean $\pm \mathrm{SD}$ ) (Curtis 2004). Immediately after tagging, all long-snouted seahorses were monitored for five minutes to check for any sign of distress; the position at which animal remained longer than two minutes was considered as a starting point for further analysis.

Underwater Visual Censuses of tagged animals were carried out by scuba divers every seven days during which data on all individuals encountered inside the stations were collected. Moreover, to intercept individuals leaving the survey area, an additional area of $30 \mathrm{~m}$ around the stations was also monitored. During dives, the tag (if present), habitat and position of fish were recorded. Untagged specimens encountered during the dives were also considered. In such a case, morphometrical measures were recorded as well.

Spatial and temporal site fidelity of tagged $H$. guttulatus were measured in terms of the home range surface and maximum distance passed from the location of initial capture. The surface of home ranges was estimated with $100 \%$ minimum convex polygon (MCP) using QGIS 2.14.22 (QGIS Development Team 2016). Only individuals with $\geq$ three re-sightings were included in the analysis. Maximum distances, corresponding to the longest movement of seahorses in any 


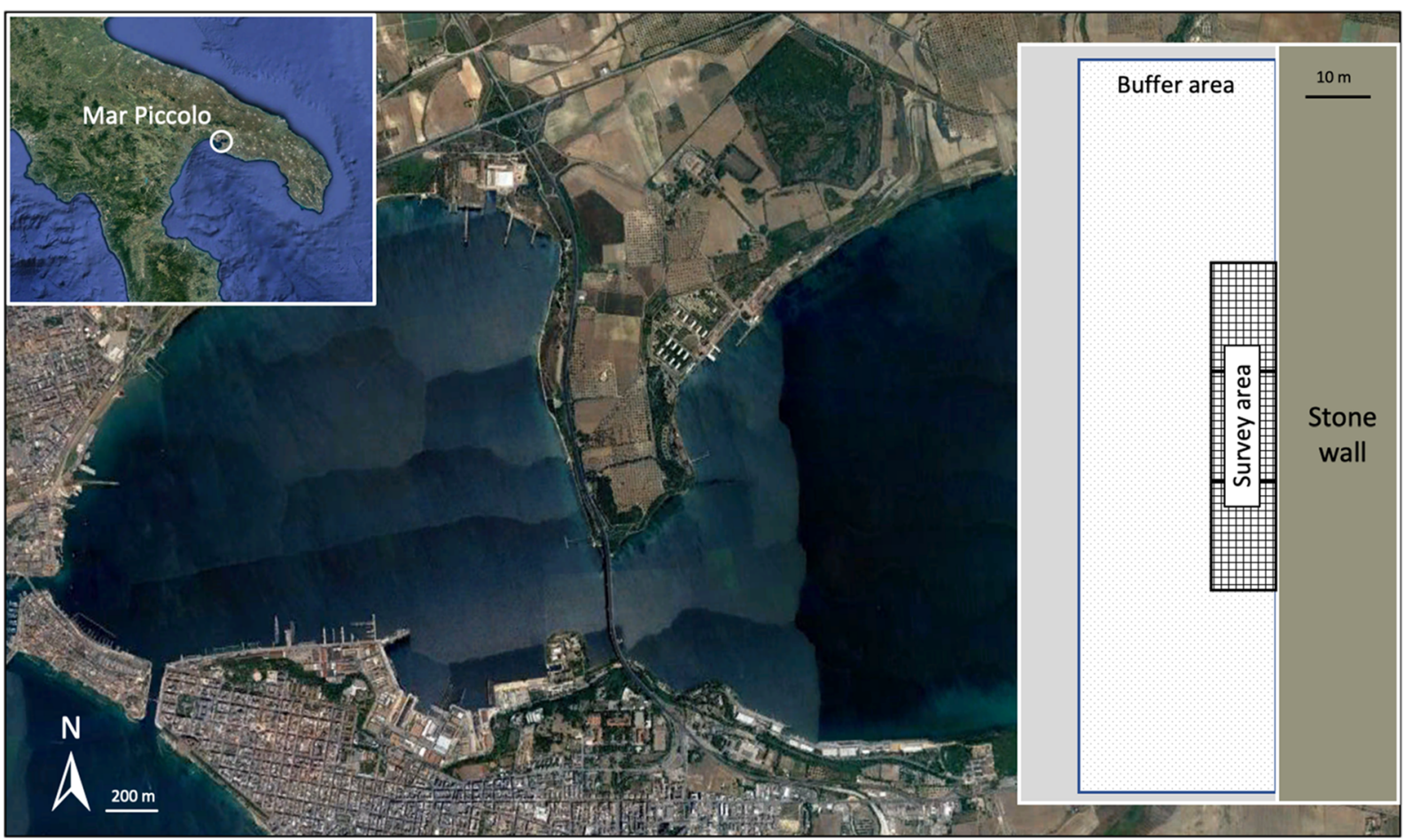

Fig. 1 Study area

direction relative to the initial capture position, were calculated using GPS coordinates in QGIS 2.14.22 (QGIS Development Team 2016).

Two sets of linear mixed models (LMMs) were used to determine if there were any interactions in both home ranges and maximum distances between sexes and lifehistory stages (adults versus juveniles) through time. All models had fitted normal distribution. A combination of four variables (sex and size as fixed factors, habitat and time as random factors) has been examined to pick the best fit of the predictor variables. ANOVA analysis was run to evaluate which model provides the best permission fit of the data. The best-fit valuation was completed using the differences in Akaike information criterion (AIC) (Akaike 1973). All statistical analyses were performed in R 3.2.2 (R Core Team 2015) environment using lmer4 (Bates et al. 2015), Matrix (Bates and Maechler 2016), MuMIn (Barton 2009) and visreg (Breheny and Burchett 2017) packages. Preliminary analyses performed over the entire experimental sample revealed high data heterogeneity which, linked to the information on average displacements, induced the use of three continuous stations as a single experimental unit to avoid excessive data dispersion.

\section{Ethical note}

All surveys were accomplished in accordance with the conditions of permit 00210337/18.09.2012 issued by the Italian Ministry of the Environment and Protection of the Land and Sea, II Division. Since stress due to the handling was minimized and procedures were carried out in situ without damaging, sacrificing or removing any seahorse from the water, approval from the Italian Institutional Animal Care and Use Committee "Organismo preposto al benessere degli animali" (O.P.B.A.) (Article 26 of the Legislative Decree No $26 / 2014$ of the Italian Republic) was not required.

\section{Results}

A total of 75 specimens of $H$. guttulatus were tagged at the beginning of two survey periods, recording $35(80 \%$ of females, $20 \%$ of males) and 40 individuals (45\% females, 55\% males) in 2016 and 2017, respectively. Tagged seahorses ranged in size from 60 to $100 \mathrm{~mm}$ (80 $\pm 11.56 \mathrm{~mm}$; mean $\pm \mathrm{SD}$ ) in 2016 and from 70 to $110 \mathrm{~mm}(90 \pm 11.89 \mathrm{~mm})$ in 2017 . In $2016,94 \%$ of 
the tagged individuals were juveniles and $8 \%$ were adults. In 2017, juveniles contributed $58 \%$ and adults $42 \%$. In 2017 , the number of individuals belonging to each category (sex versus life-cycle stage) was similar throughout the survey period, while in 2016, more juvenile females were observed (Fig. 2).

\section{Catch statistics}

Repeated surveys of the tagged individuals resulted in 186 sightings during 2016 and 256 during 2017. Two and six fish were never detected after being tagged in 2016 and 2017 , respectively. $46 \%$ of the tagged specimens were sighted less than four times in 2016, compared to $35 \%$ in 2017 . Specimens observed more than ten times comprised $9 \%$ of the total number of tagged individuals in 2016 and $20 \%$ in 2017. The highest number of sightings per single tagged seahorse was 11 in 2016 and 12 in 2017.

Overall, the highest percentage of sightings per single survey was $74.29 \%$ in 2016 (survey $\mathrm{n}^{\circ} 1$ ) and $68.29 \%$ in 2017 (survey $n^{\circ} 8$ ). Excluding the surveys in which tagged seahorses were not observed (survey $\mathrm{n}^{\circ} 16$ in 2016 and survey $\mathrm{n}^{\circ} 7$ in 2017), the lowest percentage of sightings corresponded to $5.71 \%$ in 2016 (surveys $n^{\circ} 13$ and $n^{\circ} 15$ ) and $21.95 \%$ in 2017 (surveys $n^{\circ} 7, n^{\circ} 12$ and $n^{\circ} 15$ ). During 2016, small oscillations in the number of sightings of tagged seahorses were observed between most of the surveys (average 10.41 seahorses per survey). In 2017, on average, 17.81 seahorses were encountered per survey, except on the eighth survey when an increase in the number of tagged seahorses $(n=28$ seahorses $)$ was observed (Fig. 3).
Fig. 2 Number of tagged individuals expressed as a percentage of (a) size classes (mm) in 2016 (black) and 2017 (horizontal lines), and (b) adult females, juvenile females, adult males and juvenile males at the first and last sampling event in 2016 (left) and 2017 (right)
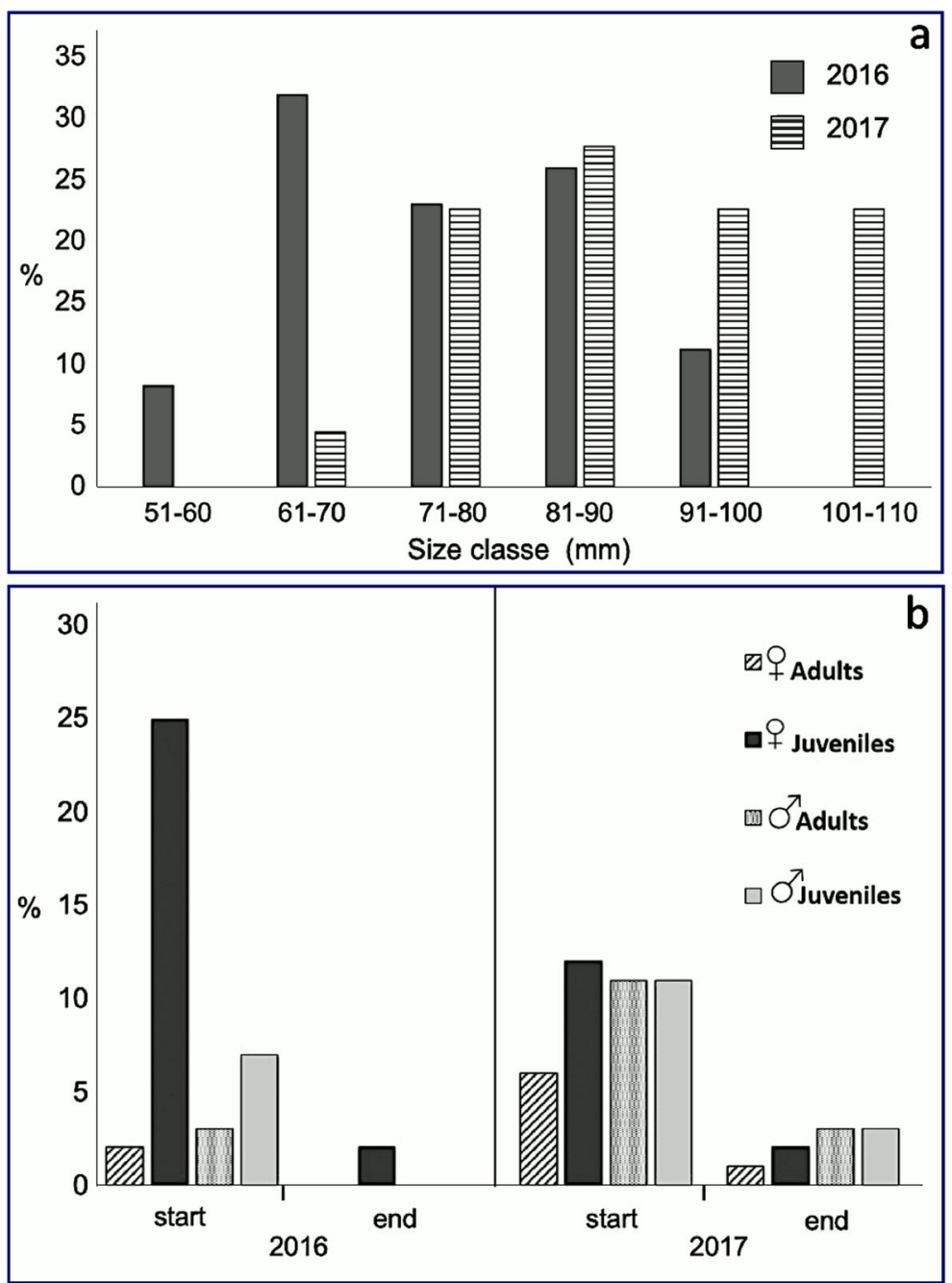


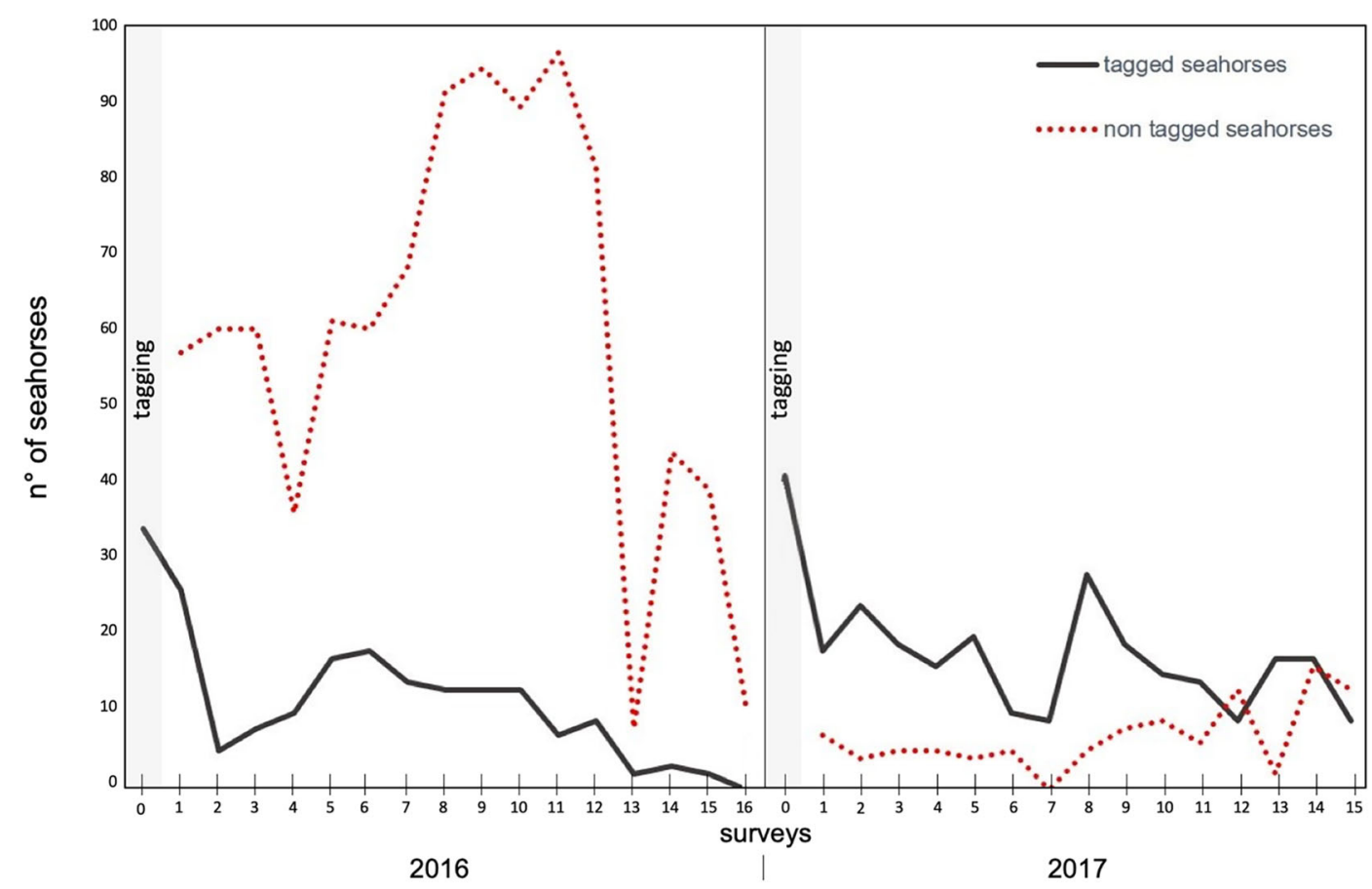

Fig. 3 Number of tagged (black line) and untagged (red dotted line) individuals observed during surveys carried out in 2016 (left) and 2017 (right)

The highest number of sightings in 2016 was achieved on the sandy bottom with rocks (SBR, $61.82 \%$ ) followed by vertical substrates (VS, 27.96\%), sandy bottom with holdfasts (SBH, 9.68\%) and uncovered sandy bottom (SB, $0.54 \%$ ). In 2017, however, most of the seahorses were re-sighted on vertical substrates ( $41.41 \%)$, sandy bottom with rocks $(35.54 \%)$ and sandy bottom with holdfasts $(22.27 \%)$, while uncovered sandy bottom resulted as the habitat with the lowest number of sightings (0.78\%) (Fig. 4).

Contemporary recordings of untagged individuals permitted to observe differences in the number of tagged and untagged seahorses in each and between survey years (Fig. 3). Untagged seahorses were monitored from the first survey (survey ${ }^{\circ} 1$ ) in both years, showing a higher number of individuals in 2016 (mean $=59.63$
Fig. 4 Distribution of tagged seahorses among habitats. VS: vertical substrates; $\mathrm{SB}$ : sandy bottom; SBH: sandy bottom with holdfasts; SBR: sandy bottom with rocks

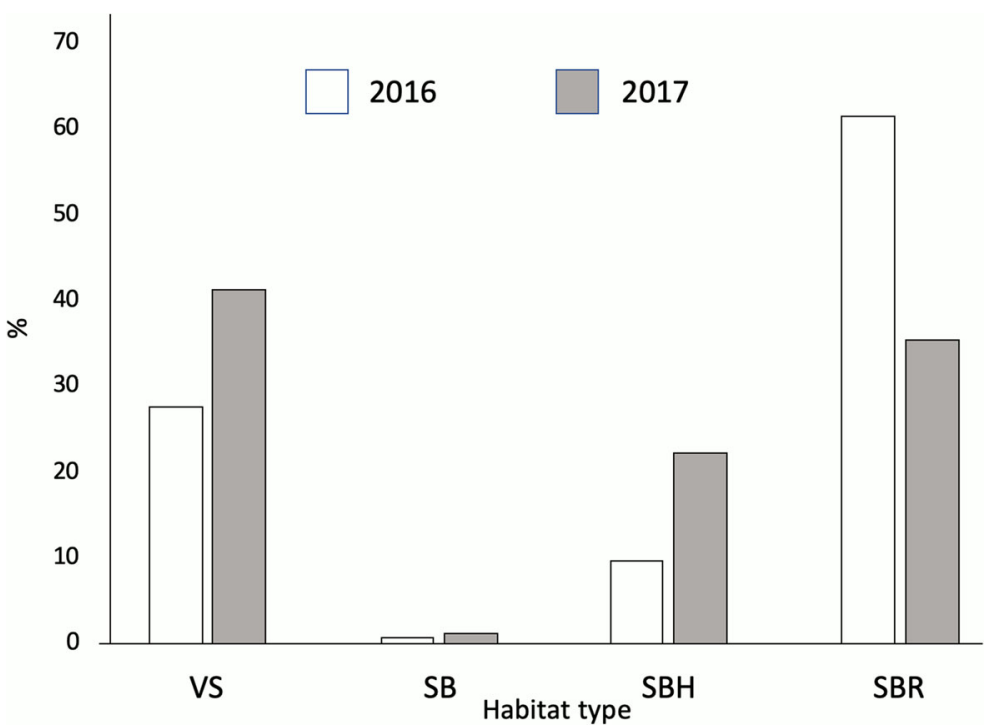


indiv., $\max =96$ indiv., $\min =8$ indiv.) than in 2017 (mean $=6.8$ indiv., $\max =16$ indiv., $\min =0$ indiv.).

\section{Home range characteristics}

Most of the tagged seahorses moved little and remained within a well-defined area over four months of monitoring during both years (Fig. 5). Indeed, average home range was $34.93 \pm 60.75 \mathrm{~m}^{2}$ (mean $\left.\pm \mathrm{SD}\right)$, while 16.87 $\pm 13.17 \mathrm{~m}^{2}$ in $2016(\mathrm{n}=28)$ and $51.25 \pm 79.99 \mathrm{~m}^{2}(\mathrm{n}=$ 31) in 2017 (Fig. 5). In particular, individual home ranges varied from 0.18 to $50.13 \mathrm{~m}^{2}$ in 2016 and from 1.92 to $441.97 \mathrm{~m}^{2}$ in 2017 . In both years, most home ranges varied between 20 and $50 \mathrm{~m}^{2}$ (35.72\% of the total number of tagged and analysed seahorses in 2016 and $29.04 \%$ in 2017) or were smaller than $20 \mathrm{~m}^{2}(32.14 \%$ in 2016 and $22.58 \%$ in 2017). However, the number of individuals with home ranges greater than $50 \mathrm{~m}^{2}$ differed among survey years: one and six individuals in 2016 and 2017, respectively, had a home range between 50 and $100 \mathrm{~m}^{2}$, while none in 2016 and three individuals in 2017 had a home range greater than $100 \mathrm{~m}^{2}$. Regarding home range in relation to the sex, the average home range was $17.54 \pm 13.01 \mathrm{~m}^{2}$ for females and $14.37 \pm$ $15.01 \mathrm{~m}^{2}$ for males in 2016 , and $62.64 \pm 114.59 \mathrm{~m}^{2}$ for females and $41.87 \pm 33.5 \mathrm{~m}^{2}$ for males in 2017 . Concerning the life-cycle stage, the average home range was $15.48 \mathrm{~m}^{2} \pm 12.63 \mathrm{~m}^{2}$ for juveniles and $34.82 \pm$ $0.76 \mathrm{~m}^{2}$ for adults in 2016 , and $56.06 \pm 106.73 \mathrm{~m}^{2}$ for juveniles and $46.13 \pm 38.1 \mathrm{~m}^{2}$ for adults in 2017 .

The average maximum distance (mean $\pm \mathrm{SD}$ ) in both years combined was $13.77 \pm 10.19 \mathrm{~m}$, while $11.09 \pm$ $7.23 \mathrm{~m}$ (range: $1-34.09 \mathrm{~m} ; \mathrm{n}=33$ ) in 2016 and 16.37 $\pm 11.95 \mathrm{~m}$ (range: $2.79-44.46 \mathrm{~m} ; \mathrm{n}=34$ ) in 2017 (Fig. 6). Most individuals showed low mobility, and in fact, $87.88 \%$ in 2016 and $73.53 \%$ of recaptures in 2017 occurred within $20 \mathrm{~m}$ from the tagging location. In 2017, more specimens (26.47\%) were found at longer distances (from 20 to $50 \mathrm{~m}$ ) than in $2016(12.12 \%)$. In both 2016 and 2017 , females $(11.39 \pm 7.87 \mathrm{~m}$ and 16.95 $\pm 12.54 \mathrm{~m}$, respectively) moved longer distances than males ( $8.37 \pm 4.66 \mathrm{~m}$ and $15.9 \pm 11.79 \mathrm{~m}$, respectively). There was also a difference between two life-cycle stages: adults $(20.79 \pm 13.63 \mathrm{~m}$ in 2016 and $18.42 \pm$ $12.29 \mathrm{~m}$ in 2017) moved longer distances respect to the juveniles in both years $(10.08 \pm 6.55 \mathrm{~m}$ in 2016 and $14.74 \pm 11.75 \mathrm{~m}$ in 2017).

Full models received the lowest AIC score for both home range and maximum distance, indicating that these models are the most parsimonious for the given dataset and included interaction between sex and lifecycle stage (Table 1). The model that explicitly demonstrated the differences among home ranges detected a significant $(\mathrm{p}<0.001)$ (Table 1$)$ and a positive increasing trend of two variables for adult females.

Results of the LMMs analyses (Fig. 7) highlighted that the differences in displacements were related to the life-cycle stage and sex for both home range and maximum distance. Both variables were higher in adults than in juveniles, as well as in females than in males. No differences were found between habitats and years. When combining sex and life-cycle stages, in 2016, adult females, with $34.82 \pm 0.76 \mathrm{~m}^{2}$ (mean $\pm \mathrm{SD}$ ) had the largest home ranges, followed by juvenile females $\left(16.62 \pm 13.21 \mathrm{~m}^{2}\right)$ and adult males $\left(15.86 \pm 12.46 \mathrm{~m}^{2}\right)$, while the smallest size of home ranges was observed in juvenile males $\left(10.71 \pm 11.94 \mathrm{~m}^{2}\right)$. In 2017 , the largest home ranges were observed in juvenile females (70.34 $\left.\pm 150.79 \mathrm{~m}^{2}\right)$, followed by adult females $(52.38 \pm$ $45.64 \mathrm{~m}^{2}$ ), while both adult and juvenile males had similar sizes of home ranges $\left(41.95 \pm 34.48 \mathrm{~m}^{2}\right.$ and $41.78 \pm 34.73 \mathrm{~m}^{2}$, respectively). Regarding maximum distances, adult females in both survey years moved greater distances $(20.79 \pm 13.63 \mathrm{~m}$ in 2016 and $21.6 \pm$ $12.39 \mathrm{~m}$ in 2017) than juvenile females $(11.08 \pm 6.97 \mathrm{~m}$ in 2016 and $13.85 \pm 12.33 \mathrm{~m}$ in 2017), adult males $(10.09 \pm 5.88 \mathrm{~m}$ in 2016 and $16.3 \pm 12.48 \mathrm{~m}$ in 2017) and juvenile males $(8.37 \pm 4.66 \mathrm{~m}$ in 2016 and $15.54 \pm$ $11.81 \mathrm{~m}$ in 2017).

\section{Discussion}

Seahorses are characterized by sedentary behaviour, small home ranges, lengthy parental care and monogamy (Foster and Vincent 2004; Curtis and Vincent 2006; Woodall 2009). These characteristics make them sensitive to the effects of anthropogenic activities and habitat loss and degradation on a worldwide level (Foster and Vincent 2004; Pollom 2017). Indeed, it is presumed that these were the causes that provoked the drastic declines in seahorse abundances throughout their geographical range, which resulted in the inclusion of the entire genus Hippocampus on the IUCN Red List of Threatened Species and Appendix II of CITES (Vincent et al. 2011; IUCN 2020). As for the Mediterranean Sea, although some data on space use of $H$. guttulatus are available (Curtis and Vincent 2006; Garrick-Maidment 

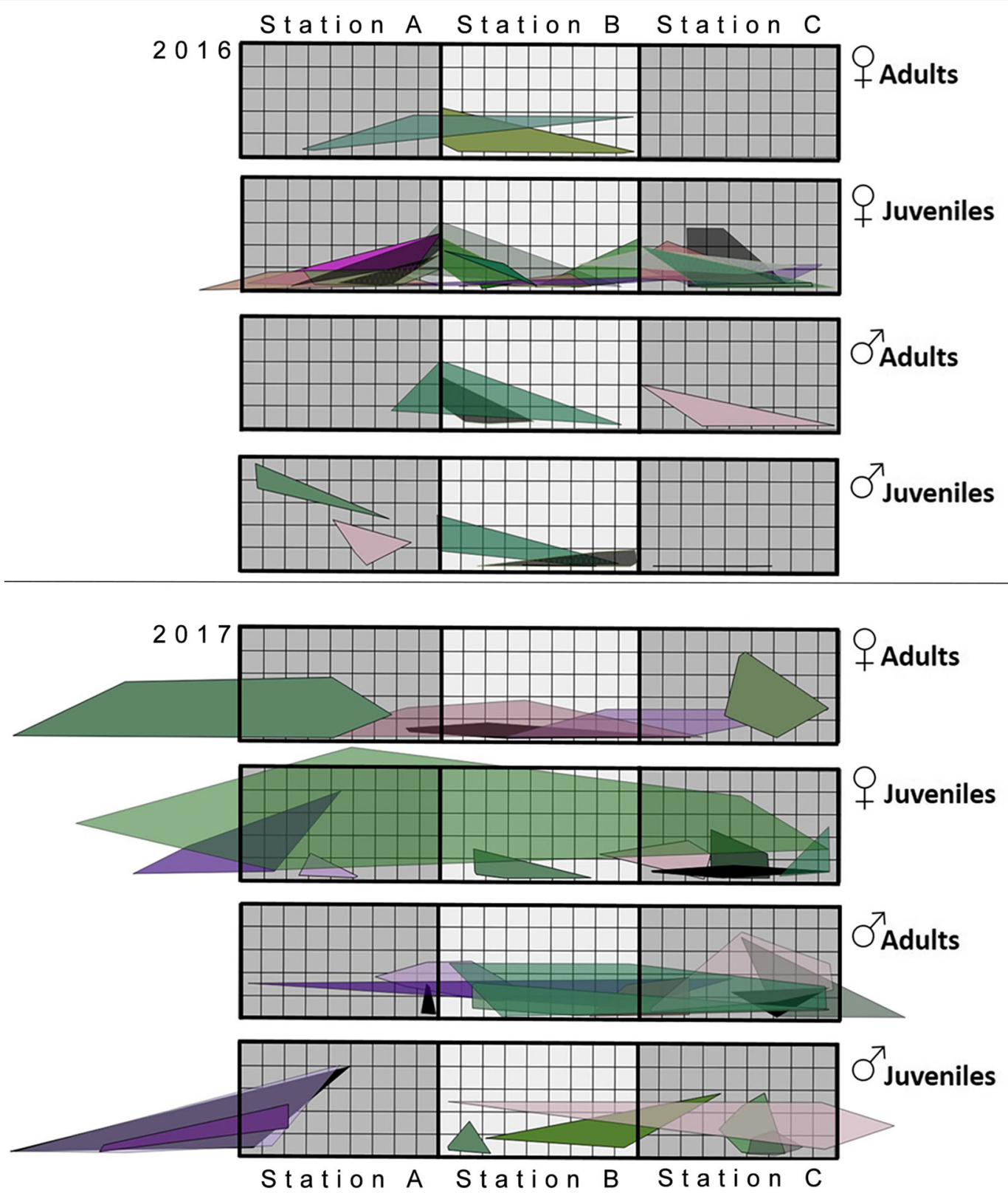

Fig. 5 The home range of tagged seahorses when sex and life-cycle stages were combined in 2016 (above) and 2017 (below). Different colours correspond to different individuals

et al. 2010; Caldwell and Vincent, 2012), further information on its ecological attributes, including spatial distribution and site fidelity, movement patterns and home range size, might be crucial for successful conservation of the species. Through mark-recapture experiment at Mar Piccolo of Taranto, a site that hosts one of the most important Mediterranean populations of seahorses (Gristina et al. 2015; Lazic et al. 2018; Ape et al. 2019), the present study allowed the arguing of the importance of considering a combination of time scales and different processes when studying $H$. guttulatus movement patterns. Data indicated an overall high site fidelity and modest species movements, but also highlighted the existence of variability among individuals, probably due to both abiotic (habitat availability) and biotic (life cycle stage, sex) factors. The observed high site fidelity was in line with the previous findings (Dauwe 1992; Moreau and Vincent 2004; Vincent et al. 


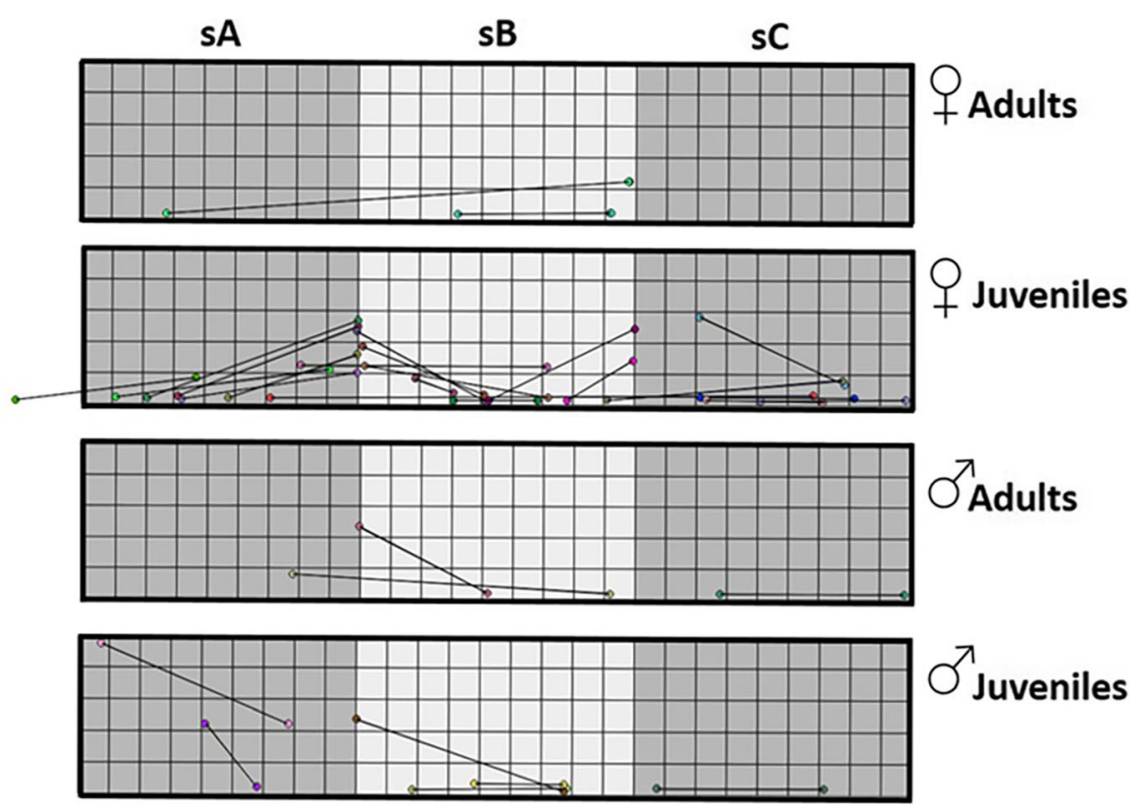

2016

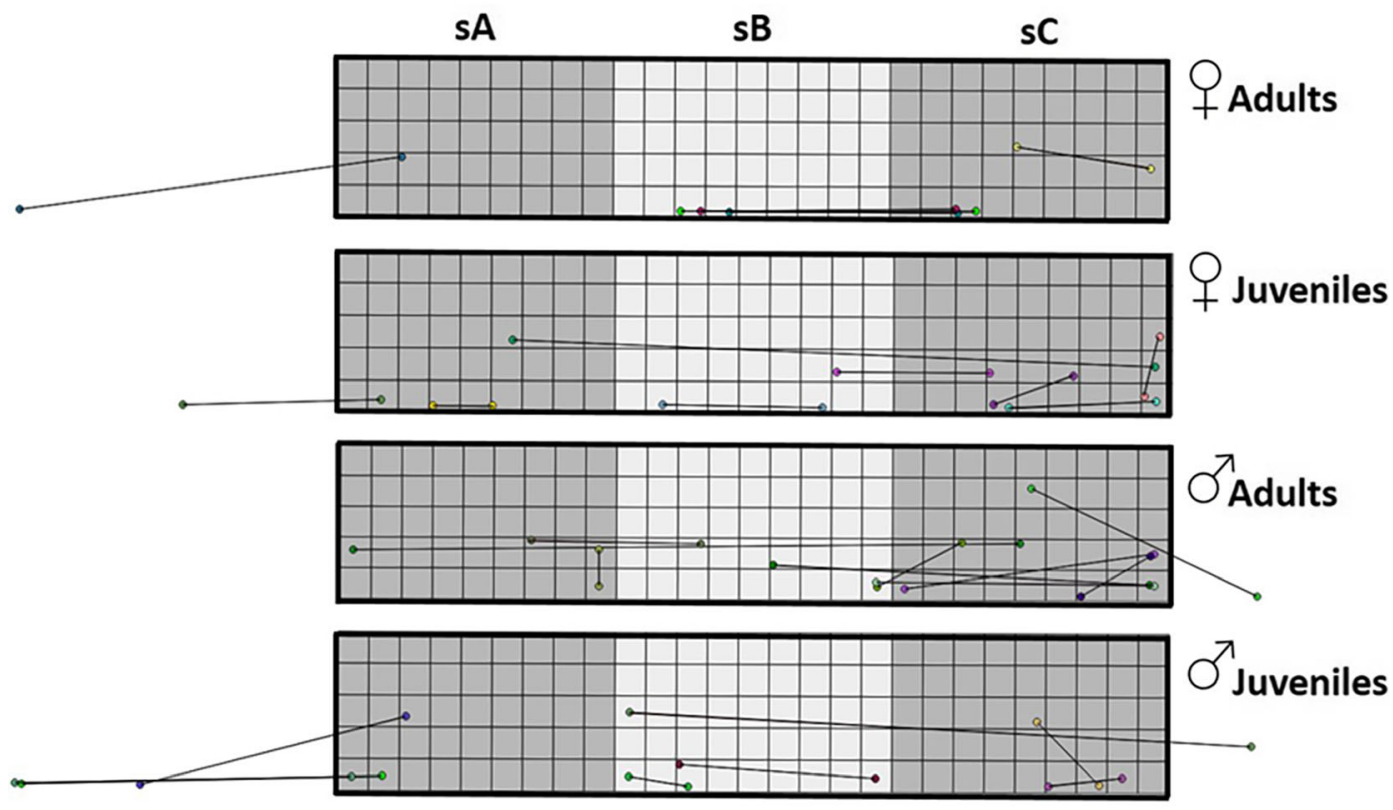

\section{7}

Fig. 6 Maximum distances passed from the tagging locations in 2016 (above) and 2017 (bellow)

2005; Curtis and Vincent 2006; Curtis et al. 2017), albeit its extent was greater compared to previously reported results on both target species (Curtis and Vincent 2006) and congeneric H. hippocampus (Curtis et al. 2017). The average home range was relatively small, but variable between the two years. Similar variability pattern was also found in maximum distance values, confirming the overall modest mobility of seahorses. Data indicated the existence of behavioural patterns linked to sex and life-cycle stages. Adult females tended to move more respect to adult males, probably because of the males' elevated metabolic rates 
Table 1 LMM and ANOVA analysis on effects of sex, size (life-cycle stage) and two factors combined on variables: maximum distance and home range size

\begin{tabular}{|c|c|c|c|c|c|c|}
\hline \multirow[b]{2}{*}{ Responsible Variable } & \multirow[b]{2}{*}{ Predictor variables } & \multicolumn{3}{|c|}{ LMM } & \multicolumn{2}{|c|}{ ANOVA } \\
\hline & & Df & AIC & $\mathrm{BIC}$ & Df & $\operatorname{Pr}(>$ Chisq $)$ \\
\hline \multirow[t]{3}{*}{ Space use } & Sex, habitat, year & 5 & 986.63 & 1007.1 & & \\
\hline & Size, habitat, year & 5 & 996.30 & 1016.8 & 0 & 1.000000 \\
\hline & Size, sex, habitat, year & 6 & 975.68 & 1000.2 & 1 & $0.0007693 * * *$ \\
\hline \multirow[t]{3}{*}{ Maximum distance } & Sex, habitat, year & 5 & 3243.2 & 3263.6 & & \\
\hline & Size, habitat, year & 5 & 3245.4 & 3265.9 & 0 & 1.000000 \\
\hline & Size, sex, habitat, year & 6 & 3236.1 & 3260.7 & 1 & $0.000001971^{* * *}$ \\
\hline
\end{tabular}

Fig. 7 Plots of Linear Mixed Models (LMMs) on home range size (left) and maximum distance (right), built by using different potential predictor factors: life cycle stage (A- adults, Jjuveniles) and sex (F- females, Mmales). SB: Sandy Bottoms; SBH: Sandy Bottoms with Holdfasts; SBR: Sandy Bottoms with Rocks; VS: Vertical Substrates

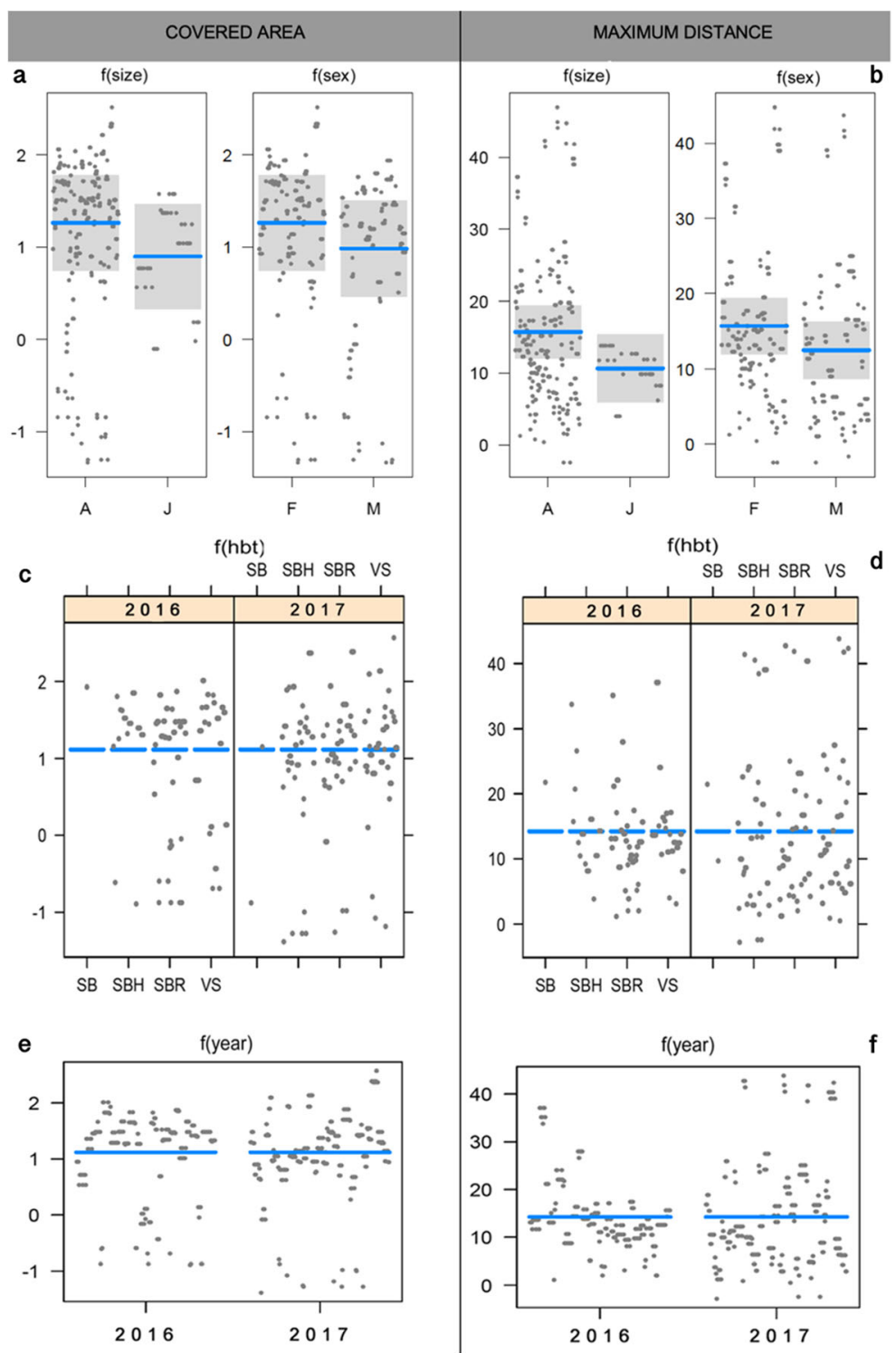


following pregnancy and brood care (Masonjones and Lewis 2000) which would favour reduced movements; indeed, pregnant males have been constantly observed at least until November, probably because of the favourable seawater temperatures at this site. The differences in movement degree have been already associated with reproductive behaviour in seahorse species (Vincent and Sadler 1995; Perante et al. 2002; Bell et al. 2003; Vincent et al. 2005; Curtis and Vincent 2006; Freret-Meurer and Andreata 2008; FreretMeurer et al. 2012; Boehm et al. 2015).

As for habitats, analyses did not reveal the existence of any relationship between habitat types and movement degree neither in terms of home range sizes nor in maximum distances. The availability of multiple habitats can induce specimens to choose and remain in a restricted area by moving from one habitat to another, which is an observation that seems consistent with the patchy distribution of seahorses (Curtis and Vincent 2005; Lazic et al. 2018). However, the results of the present study indicated the seahorse preferences towards complex habitats (such as VS, rich in both animal and vegetal communities, and SBR in which many algal species grow), following previous studies (Gristina et al. 2017; Lazic et al. 2018), and the higher density of individuals in these habitats did not induce greater movements. The lack of a higher degree of movements in relation to available habitats may indicate that the area suitability is evaluated on much broader geographical scales than at those in which habitats alternate rapidly, as was the case in this study.

Information on the movement degree of sedentary fish can provide, directly or indirectly, insights into the conservation status of habitats and can help define their suitability when under changes. The species behaviour is commonly linked to the access to necessary resources, such as food, shelter and mating while opting for minimal movements (Krebs and Davies 1997). Therefore, it should be expected that sedentary fish will move away when local environmental conditions become unsuitable for survival, growth or reproduction. Correia et al. (2018) have demonstrated that both environmental variables (temperature, light, holdfast availability and food) and population density can affect the mobility of seahorses, and indeed, closely positioned seahorses have a lower tendency to move (Caldwell and Vincent 2012). Respect to the literature data, the results of the present study have shown that $H$. guttulatus has a slightly increased tendency for movements, presumably indicating the existence of stressing factors. Although the observed movement pattern could have multiple causes, including environmental and intraspecific variability, anthropogenic disturbances and density changes could have also affected the local community. However, the drastic reduction in the number of individuals observed in both years, and in particular in 2017, could partially explain the movement pattern.

Mar Piccolo of Taranto is characterized by particular environmental and biochemical properties (Caroppo et al. 2012). It is a semi-enclosed basin, in which hypoxic events can occur during summer when slower circulation and warmer temperatures can cause the increase of the bottom respiration, impacting, therefore, not just benthic habitats but also potential prey organisms (Caroppo et al. 2012). Furthermore, various fishing activities on molluscs and other edible organisms take place in the basin. These activities impact the substrate consistency but also directly influence the population dynamics of numerous species. Indeed, the seahorse population showed a high density of juveniles and the absence of large reproductive adults (above $100 \mathrm{~mm} \mathrm{SL}$ ) in 2016. Although a high number of young recruits could indicate a good ecological state of the population, the lack of large reproductive individuals seems to confirm the consistent disturbance events. Indeed, in 2017, the population underwent a shift towards larger sizes (above $100 \mathrm{~mm} \mathrm{SL}$ ) with the disappearance of smaller recruits (below $60 \mathrm{~mm} \mathrm{SL}$ ). Besides, at the end of the first year's surveys (January 2017), only juvenile females were present in the investigated area. At least partially, the effects of anthropic disturbances may also have been responsible for the observed variations in the occurrence of seahorses among habitats. Indeed, it seems that seahorses preferred different habitats in two consecutive years since most of them were found in SBR during 2016 and in VS during 2017. Since fishing activities that use static or mobile gears mainly operate on horizontal uncovered bottoms, habitats on vertical substrates could be more conserved (Gristina et al. 2017), and as such, could represent a refuge area for many species.

Although the disappearance of an important population fraction $(17.5 \%$ of the tagged individuals and approximately $50 \%$ reduction of the total population) during 2017 may have natural causes (e.g. Boehm et al. 2015), such as turnover of individuals or migration to deeper waters due to worsening weather conditions in winter, it is important to point out that a similar 
phenomenon has never been observed in more than ten years of monitoring in the same area (Gristina et al. 2015, 2017; Lazic et al. 2018; Ape et al. 2019). The observed scenario may have several explanations, including that tagged seahorses could have left the study area, thereby indicating a greater home range than assumed. Secondly, they could have been hidden, but this is unlikely since surveys were always performed by three divers that examined the area in detail. Lastly, they could have been caught supporting, in that case, indications of seahorse harvesting. Indeed, it has been recently published a report (https://veraleaks.org/) confirming the presence of an illicit seahorse trade for the needs of the Asian market. This new threat to the seahorse population could have had a dramatic effect and could help explain the sudden decrease in the number of specimens in 2017. Effectively, direct exploitation of seahorses for commercial purposes could be a stressor leading to density reduction (Foster and Vincent 2004; Vincent et al. 2011; Stocks et al. 2019), which is a scenario that appears even more critical when the reduction occurs in one of the most important seahorse populations in the Mediterranean Sea (Gristina et al. 2015; Lazic et al. 2018). Taranto Mar Piccolo, indeed, represents an important ecological and genetic resource for the entire Mediterranean seahorse population, because of both high population density (Gristina et al. 2015; Lazic et al. 2018) and peculiar genetic traits (Lazic et al. 2020, in press). However, despite the protection regime dictated by international protocols, there is a lack of effective laws and tools allowing their local conservation. Low mobility and inhabitation of shallow habitats, where numerous anthropic activities are carried out, mean that Taranto Mar Piccolo's seahorses are more threatened and exposed to risks which, in the long run, could compromise their ecological stability. Therefore, it is necessary to identify and quantify the sources of disturbances while measuring the species responses to them. The results of the present study demonstrated that small-scale phenomena, such as the presence of suitable habitats and variability of home range, should be considered in the design of efficient conservation strategies.

Acknowledgements The authors would like to thank the three anonymous reviewers whose thoughtful suggestions permitted the critical revision of the manuscript.
Funding Information Open access funding provided by Università degli Studi di Bari Aldo Moro within the CRUICARE Agreement.

Open Access This article is licensed under a Creative Commons Attribution 4.0 International License, which permits use, sharing, adaptation, distribution and reproduction in any medium or format, as long as you give appropriate credit to the original author(s) and the source, provide a link to the Creative Commons licence, and indicate if changes were made. The images or other third party material in this article are included in the article's Creative Commons licence, unless indicated otherwise in a credit line to the material. If material is not included in the article's Creative Commons licence and your intended use is not permitted by statutory regulation or exceeds the permitted use, you will need to obtain permission directly from the copyright holder. To view a copy of this licence, visit http://creativecommons.org/licenses/by/4.0/.

\section{References}

Akaike H (1973) Information theory and an extension of the maximum likelihood principle. In: Petrov $\mathrm{BN}$, Csaki $\mathrm{F}$ (eds) International Symposium on Information Theory. Akademia Kiado, Budapest, pp $267-81$

Ape F, Corriero G, Mirto S, Pierri C, Lazic T, Gristina M (2019) Trophic flexibility and prey selection of the wild longsnouted seahorse Hippocampus guttulatus Cuvier, 1829 in three coastal habitats. Estuar Coast Shelf Sci 224:1-10. https://doi.org/10.1016/j.ecss.2019.04.034

Barton K (2009) Mu-MIn: Multi-model inference. http://R-Forge. R-project.org/projects/mumin

Bates D, Maechler M (2016) Matrix: Sparse and dense matrix classes and methods. http://CRAN.R-project.org/package=Matrix

Bates D, Machler M, Bolker B, Walker S (2015) Fitting Linear Mixed-Effects Models using lme4. J Stat Softw 67:1-48. https://doi.org/10.18637/jss.v067.i01

Bell EM, Lockyear JF, McPherson JM, Marsden AD, Vincent ACJ (2003) The first field studies of an endangered South African seahorse, Hippocampus capensis. Environ Biol Fish 67:35-46. https://doi.org/10.1023/A:1024440717162

Boehm JT, Waldman J, Robinson JD, Hickerson MJ (2015) Population Genomics Reveals Seahorses (Hippocampus erectus) of the Western Mid-Atlantic Coast to Be Residents Rather than Vagrants. PLoS One 10(1):e0116219. https://doi. org/10.1371/journal.pone.0116219

Botsford LW, Brumbaugh DR, Grimes C, Kellner JB and others (2009) Connectivity, sustainability, and yield: bridging the gap between conventional fisheries management and marine protected areas. Rev Fish Biol Fish 19:69-95. https://doi. org/10.1007/s11160-008-9092-Z

Breheny P, Burchett W (2017) Visualization of Regression Models Using visreg. R J 9:56-71. https:/journal.r-project. org/archive/2017/RJ-2017-046/index.html

Brown JH, Gillooly JF, Allen AP, Savage VM, West GB (2004) Toward a metabolic theory of ecology. Ecology 85:17711789. https://doi.org/10.1890/03-9000 
Burger J, Gochfeld M (2001) On developing bioindicators for human and ecological health. Environ Monit Assess 66:2346. https://doi.org/10.1023/A:1026476030728

Caldwell JR, Vincent ACJ (2012) Revisiting two sympatric European seahorse species: Apparent decline in the absence of exploitation. Aquat Conserv 22:427-435. https://doi. org/10.1002/aqc. 2238

Caldwell IR, Vincent ACJ (2013) A sedentary fish on the move: effects of dis-placement on long-snouted seahorse (Hippocampus guttulatus Cuvier) movement and habitat use. Environ Biol Fish 96:67-75. https://doi.org/10.1007 /s10641-012-0023-4

Caroppo C, Giordano L, Palmieri N, Bellio G, Paride Bisci A, Portacci G, Sclafani P, Sawyer Hopkins T (2012) Progress toward sustainable mussel aquaculture in Mar Piccolo, Italy. Ecol Soc 17:10. https://doi.org/10.5751/ES-04950-170310

Clark RP (2000) Global life systems: Population, food, and disease in the process of globalization. Rowman and Littlefield Publishers, Lanham

Correia M (2015) Trends in seahorse abundance in the Ria Formosa, South Portugal: recent scenario and future prospects. Dissertation, Universidade do Algarve, Portugal

Correia M, Koldewey HJ, Andrade JS, Esteves E, Palma J (2018) Identifying key environmental variables of two seahorse species (Hippocampus guttulatus and Hippocampus hippocampus) in the Ria Formosa lagoon, South Portugal. Environ Biol Fish 101: 1357-1368. https://doi.org/10.1007/s10641-018-0782-7

Curtis JMR (2004) Life history, ecology and conservation of European seahorses. Dissertation, McGill University, Canada

Curtis JMR, Vincent ACJ (2005) Distribution of sympatric seahorse species along a gradient of habitat complexity in a seagrass - dominated community. Mar Ecol Prog Ser 291: 81-91. https://doi.org/10.3354/meps291081

Curtis JMR, Vincent ACJ (2006) Life history of an unusual marine fish: Survival, growth and movement patterns of Hippocampus guttulatus Cuvier 1829. J Fish Biol 68:707733. https://doi.org/10.1111/j.0022-1112.2006.00952.x

Curtis JMR, Moreau MA, Marsden D, Bell E, Martin-Smith K, Samoilys M, Vincent A (2004) Underwater visual census for seahorse population assessments. Project Seahorse, University of British Columbia, Vancouver

Curtis JMR, Santos SV, Nadeau JL, Gunn B, Bigney Wilner K, Balasubramanian $\mathrm{H}$, Overington S, Lesage C-M, d'Entremont J, Wieckowski K (2017) Life history and ecology of the elusive European short-snouted seahorse, Hippocampus hippocampus. J Fish Biol 91:1603-1622. https://doi.org/10.1111/jfb.13473

Dauwe B (1992) Ecology of the seahorse Hippocampus reidi on the Bonaire coral reef (N.A.): habitat, reproduction and community interactions. Dissertation, University of Groningen, Netherlands

Foster SJ, Vincent ACJ (2004) Life history and ecology of seahorses: implications for conservation and management. $J$ Fish Biol 65:1-61. https://doi.org/10.1111/j.00221112.2004.00429.x

Freret-Meurer NV, Andreata JV (2008) Field studies of a Brazilian seahorse population, Hippocampus reidi Ginsburg, 1933. Braz Arch Biol Technol 51:743-751. https://doi. org/10.1590/S1516-89132008000400012
Freret-Meurer NV, Andreata JV, Alves MAS (2012) Activity rate of the seahorse Hippocampus reidi Ginsburg, 1933 (Syngnathidae). Acta Ethol 15:221-227. https://doi. org/10.1007/s10211-012-0125-1

Gage GS, Brooke MDL, Symonds MRE, Wege D (2004) Ecological correlates of the threat of extinction in Neotropical bird species. Anim Conserv 7:161-168. https://doi.org/10.1017/S1367943004001246

Garrick-Maidment N, Trewhella S, Hatcher J, Collins KJ, Mallinson JJ (2010) Seahorse tagging project, Studland Bay, Dorset, UK. Mar Biodivers Rec 3:e73. https://doi. org/10.1017/S175526721000062X

Gehring TM, Swihart RK (2004) Home range and movements of long-tailed weasels in a landscape fragmented by agriculture. J Mammal 85:79-86. https://doi.org/10.1644/1545-1542 (2004)085<0079:HRAMOL>2.0.CO;2

Gristina M, Cardone F, Carlucci R, Castellano L, Passarelli S, Corriero G (2015) Abundance, distribution and habitat preference of Hippocampus guttulatus and Hippocampus hippocampus in a semi-enclosed central Mediterranean marine area. Mar Ecol 36:57-66. https://doi.org/10.1111/maec.12116

Gristina M, Cardone F, Desiderato A, Mucciolo S, Lazic T, Corriero G (2017) Habitat use in juvenile and adult life stages of the sedentary fish Hippocampus guttulatus. Hydrobiologia 784:9-19. https://doi.org/10.1007/s10750-016-2818-3

Hansen EA, Closs GP (2005) Diel activity and home range size in relation to food supply in a drift-feeding stream fish. Behav Ecol 16:640-648. https://doi.org/10.1093/beheco/ari036

Haskell JP, Ritchie ME, Olff H (2002) Fractal geometry predicts varying body size scaling relationships for mammal and bird home ranges. Nature 418:527-530. https://doi.org/10.1038 /nature 00840

Işik K (2011) Rare and endemic species: Why are they prone to extinction? Turk J Bot 35:411-417. https://doi.org/10.3906 /bot-1012-90

IUCN (2020) The IUCN Red List of Threatened Species. Available at http://www.iucnredlist.org

Jones CM, Braithwaite VA, Healy SD (2003) The evolution of sex differences in spatial abilities. Behav Neurosci 117:403-411. https://doi.org/10.1037/0735-7044.117.3.403

Kjellander P, Hewison AJM, Liberg O, Angibault JM, Bideau E, Cargnelutti B (2004) Experimental evidence for densitydependence of home-range size in roe deer (Capreolus capreolus L.): a comparison of two long-term studies. Oecologia 139:478-485. https://doi.org/10.1007/s00442004-1529-z

Klein CJ, Tulloch VJ, Halpern BS, Selkoe KA, Watts ME, Steinback C, Scholz A, Possingham HP (2013) Tradeoffs in marine reserve design: habitat condition, representation, and socioeconomic costs. Conserv Lett 6:324-332. https://doi. org/10.1111/conl.12005

Krebs JR, Davies NB (1997) Behavioural Ecology: An evolutionary approach. Blackwell, Oxford

Lazic T, Pierri C, Gristina M, Carlucci R, Cardone F, Colangelo P, Desiderato A, Mercurio M, Bertrandino MS, Longo C, Carbonara P, Corriero G (2018) Distribution and habitat preferences of Hippocampus species along the Apulian coast. Aquat Conserv 28:1317-1328. https://doi.org/10.1002/aqc.2949

Louisy P (2011) Hippocampus guttulatus, l'espèce commune de l'étang de Thau, Hippo-Thau Bilan Scientifique 2005-2009. CPIE, Bassin de Thau, France 
Lourie SA, Vincent AC, Hall H (1999) Seahorses: an identification guide to the world's species and the conservation. Project Seahorse and TRAFFIC North America, University of British Columbia and World Wildlife Fund

Lourie SA, Pollom RA, Foster SJ (2016) A global revision of the seahorses Hippocampus Rafinesque 1810 (Actinopterygii: Syngnathiformes): taxonomy and biogeography with recommendations for further research. Zootaxa 4146:1-66. https://doi.org/10.11646/zootaxa.4146.1.1

Masonjones HD, Lewis SM (2000) Differences in potential reproductive rates of male and female seahorses related to courtship roles. Anim Behav 59:11-20. https://doi.org/10.1006 /anbe.1999.1269

Moreau MA, Vincent ACJ (2004) Social structure and space use in a wild population of the Australian short-headed seahorse Hippocampus breviceps Peters, 1869. Mar Freshw Res 55: 231-239. https://doi.org/10.1071/MF03159

Naylor E (2005) Chronobiology: implications for marine resource exploitation and management. Sci Mar 69:157-167. https://doi.org/10.3989/scimar.2005.69s1157

Oro D (2013) Grand challenges in population dynamics. Frontiers in Ecology and Evolution. https://doi.org/10.3389 /fevo.2013.00002

Perante NC, Pajaro MG, Meeuwig JJ, Vincent ACJ (2002) Biology of a seahorse species Hippocampus comes in the central Philippines. J Fish Biol 60:821-837. https://doi. org/10.1111/j.1095-8649.2002.tb02412.x

Pittman SJ, McAlpine CA (2003) Movements of marine fish and decapod crustaceans: process, theory and application. Adv Mar Biol 44:205-294. https://doi.org/10.1016/S0065-2881 (03)44004-2

Pollom R (2016) Hippocampus guttulatus. The IUCN Red List of Threatened Species 2016: e.T10069A90866381. Downloaded on 03 January 2020

Pollom R (2017) Hippocampus guttulatus. The IUCN Red List of Threatened Species 2017. https://doi.org/10.2305/IUCN. UK.2017-3.RLTS.T41006A67617766.en. Accessed 16 Dec 2019

QGIS Development Team (2016) QGIS Geographic Information System. Open Source Geospatial Foundation Project. http://qgis.osgeo.org
R Core Team (2015) R: A language and environment for statistical computing. R Foundation for Statistical Computing. https://www.R-project.org

Relini G, Tunesi L, Vacchi M, Andaloro F, D’Onghia G, Fiorentino F, Fiorentino F, Garibaldi F, Orsi Relini L, Serena F, Silvestri R, Battistoni A, Teofili C, Rondinini C (2017) Lista Rossa IUCN dei Pesci ossei marini Italiani. Comitato Italiano IUCN e Ministero dell'Ambiente e della Tutela del Territorio e del Mare. Accessed 10 Dec 2019

Selig ER, Turner WR, Troëng S, Wallace BP, Halpern BS, Kaschner K, Lascelles BG, Carpenter KE, Mittermeier RA (2014) Global priorities for marine biodiversity conservation. PLoS One 9:e82898. https://doi.org/10.1371/journal. pone. 0082898

Stocks AP, Foster SJ, Bat NK, Ha NM, Vincent ACJ (2019) Local Fishers' Knowledge of Target and Incidental Seahorse Catch in Southern Vietnam. Hum Ecol 47:394-408. https://doi. org/10.1007/s10745-019-0073-8

Vincent ACJ, Sadler LM (1995) Faithful pair bonds in wild seahorses, Hippocampus whitei. Anim Behav 50:15571569. https://doi.org/10.1016/0003-3472(95)80011-5

Vincent ACJ, Evans KL, Marsden AD (2005) Home range behaviour of the monogamous Australian seahorse, Hippocampus whitei. Environ Biol Fish 72:1-12. https://doi.org/10.1007 /s10641-004-4192-7

Vincent ACJ, Foster SJ, Koldewey HJ (2011) Conservation and management of seahorses and other syngnathids. J Fish Biol 78:1681-1724. https://doi.org/10.1111/j.10958649.2011.03003.x

Willis TJ, Badalamenti F, Milazzo M (2006) Diel variability in counts of reef fishes and its implications for monitoring. $\mathrm{J}$ Exp Mar Biol Ecol 331:108-120. https://doi.org/10.1016/j. jembe.2005.10.003

Woodall L (2009) Population genetics and mating systems of European seahorses Hippocampus guttulatus and Hippocampus hippocampus. Dissertation, University of London, UK

Publisher's Note Springer Nature remains neutral with regard to jurisdictional claims in published maps and institutional affiliations. 